Special issue of the 2nd International Conference on Computational and Experimental Science and Engineering (ICCESEN 2015)

\title{
Shielding Behaviors and Analysis of Mechanical Treatment of Cements Containing Nanosized Powders
}

\author{
H. MutuK ${ }^{a, *}$, T. MutuK ${ }^{b}$, H. GÜmÜş ${ }^{a}$ And B. Mesci OKtaY ${ }^{b}$ \\ ${ }^{a}$ Ondokuz Mayis University, Faculty of Arts and Sciences, Department of Physics, Samsun, Turkey \\ ${ }^{b}$ Ondokuz Mayis University, Faculty of Engineering, Department of Material Science and Engineering, \\ Samsun, Turkey
}

\begin{abstract}
In this study, we investigated linear attenuation coefficient $(\mu)$, half value layer, tenth value layer at 243,344 ,

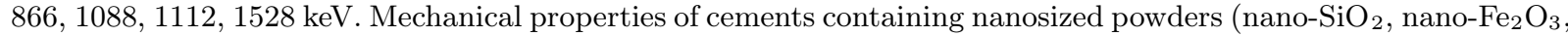
nano- $\mathrm{Al}_{2} \mathrm{O}_{3}$ ) are obtained. According to compressive strength results nano- $\mathrm{SiO}_{2}$ added cementitious material gave the highest strength. Moreover, all the nanopowders added samples showed higher compressive strength with respect to reference sample. The experimental linear mass attenuation coefficients $\mu$, half value layer, tenth value layer for cementitious material were compared with theoretical values obtained using XCOM. The experimental results were found to be in good agreement with the theoretical values.
\end{abstract}

DOI: 10.12693/APhysPolA.130.172

PACS/topics: 28.41.Qb, 34.50.Bw, 81.05.Rm, 81.70.Bt

\section{Introduction}

Cement and eventually concrete is the basic industry in all over the world. Concrete is the fundamental ingredient for construction of buildings so far. It is an important tool to study its mechanical and chemical properties such as compressive strength, durability as well as its radiation shielding properties. In recent years, nanoparticles are being used as cement replacing materials for producing ecologic concrete. The addition of nanosized particles improves the performance of cement. Besides that, concrete can be used as a shielding material for various purposes. Conventional gamma ray shielding materials are lead and concrete. Many studies are being done to determine these coefficients and to improve it. These can be found in Refs. [1-11]. In this study, we aimed to investigate both mechanical treatment and radiation shielding property of nanosized powders added cementitious materials.

\section{Materials, methods and results}

The first parameter to calculate is $\mu$, the linear attenuation coefficient, and is given by

$$
I=I_{0} \exp (-\mu x) \text {, }
$$

where $I$ and $I_{0}$ are the attenuated and incident gamma ray intensities, respectively and $x$ is the thickness of the sample.

The half value layer (HVL) is the thickness of the material where one half of the incident photons is attenuated.

It can be calculated via

$$
\mathrm{HVL}=\frac{0.693}{\mu} \text {. }
$$

\footnotetext{
*corresponding author; e-mail: halil.mutuk@omu.edu.tr
}

Last parameter to be calculated is tenth value layer (TVL) which is the thickness of the shielding material where one tenth of the incident photons is attenuated

$$
\mathrm{TVL}=\frac{2.3026}{\mu} .
$$

The nanosized structures such as nanopowders have a very large surface to volume ratio. This features change physico-chemical properties and also increase chemical activity. For this reason, it is an ideal tool to study manufacturing these materials and their applications in recent years. Two of authors (T. Mutuk and B.M. Oktay) aimed to produce a cementitious material which has less pore ratio and also mechanical treatment which is more by using nanopowders (nano- $\mathrm{SiO}_{2}$, nano- $\mathrm{Fe}_{2} \mathrm{O}_{3}$, nano$\mathrm{Al}_{2} \mathrm{O}_{3}$ ) in cement [12]. The percentage of nanopowders was used as $1 \%$ into the cementitious material. Sample mixtures were made of $1350 \mathrm{~g}$ sand, $450 \mathrm{~g}$ cement and $225 \mathrm{ml}$ of water. Mortar samples of size $4 \times 4 \times 4 \mathrm{~cm}^{3}$ cubic prisms were manufactured. The ordinary portland cement (OPC) which was used in this study is CEM I 42.5 as classified by the TS-EN 196-1 standard. In this study we used an experimental setup shown in Fig. 1. The detector system including a $10 \mathrm{~cm}$ diameter $\mathrm{NaI}(\mathrm{Tl})$ detector by ORTEC Inc., connected to a multichannel pulse height analyzer are used. The sample was placed between the ${ }^{152} \mathrm{Eu}$ source and the detector. The measurements have been carried out in the range from 244 to $1528 \mathrm{keV}$. The measured photon attenuation coefficients $\mu$, HVL, TVL were compared with the calculations obtained by using XCOM [13].

The linear attenuation coefficients $\mu$, HVL, TVL for cementitious material have been measured and calculated at $243,344,866,1088,1112$ and $1528 \mathrm{keV}$. Results are shown in Fig. 2 and Fig. 3. Table I shows physical properties and mechanical treatment for 28 days of nanopowders added cementitious materials. 


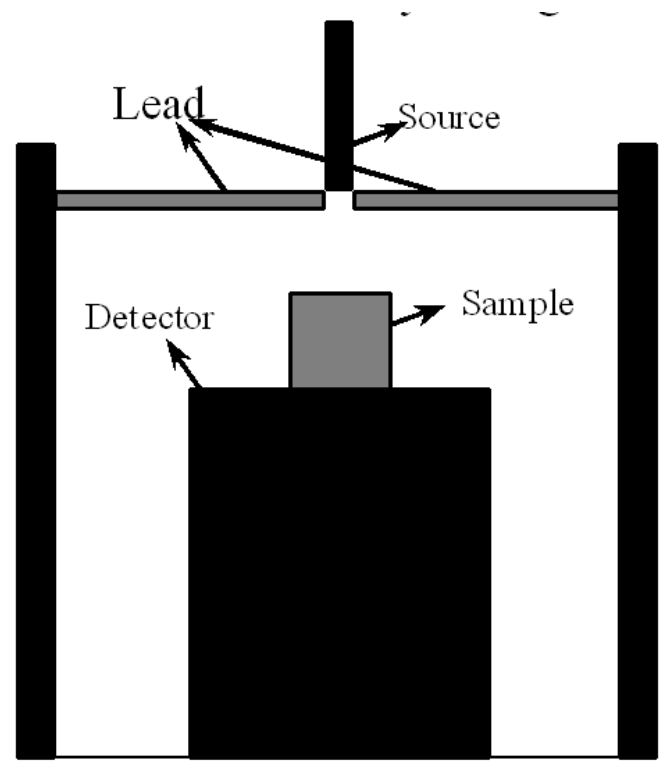

Fig. 1. Experimental setup.

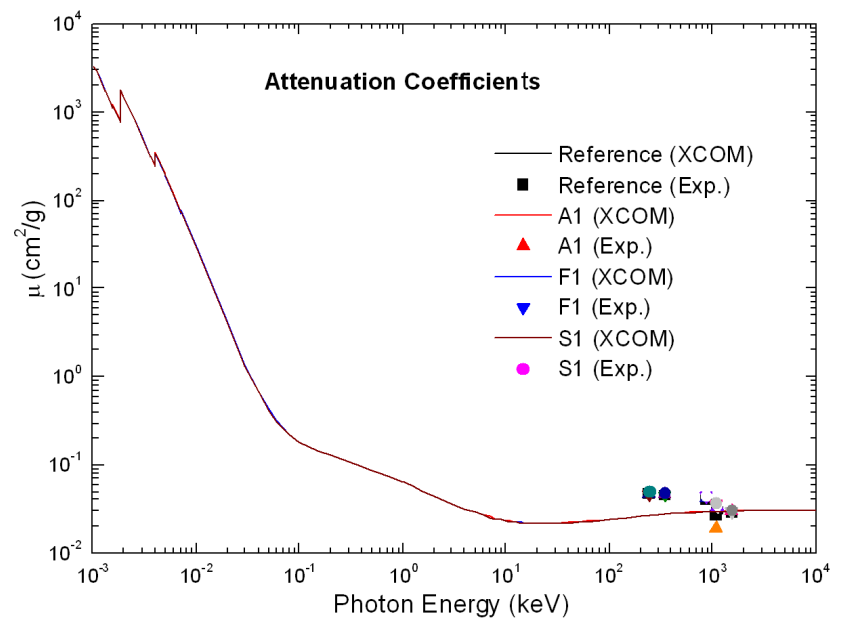

Fig. 2. Linear attenuation coefficients.

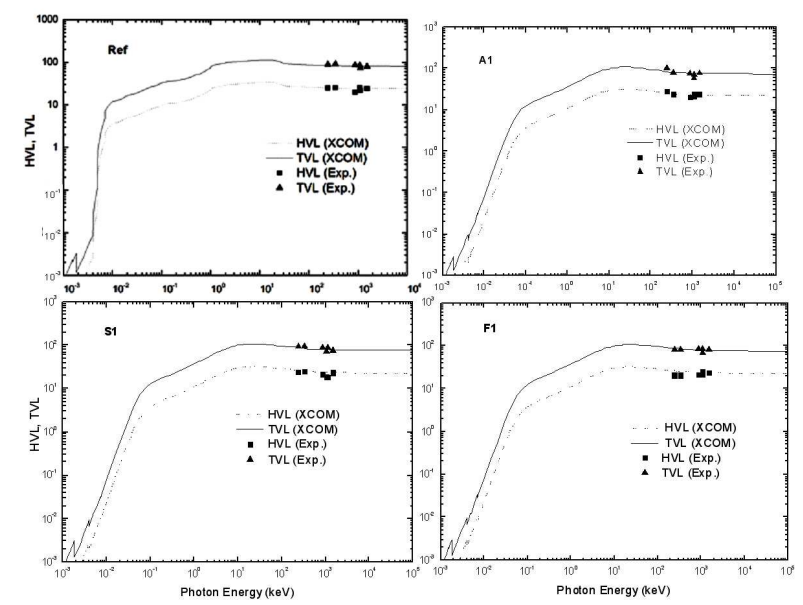

Fig. 3. HVL and TVL results of the samples.
TABLE I

Physical properties of nanopowders and mechanical strength of nanopowders added samples.

\begin{tabular}{c|c|c|c|c}
\hline \hline \multicolumn{3}{c|}{ Physical properties of nanopowders } & \multicolumn{2}{|c}{$\begin{array}{c}\text { Mechanical strength } \\
\text { of nanopowders } \\
\text { added samples }\end{array}$} \\
\hline Nanopowder & $\begin{array}{c}\text { Particle } \\
\text { size [nm] }]\end{array}$ & $\begin{array}{c}\text { Specific surface } \\
\text { area }\left[\mathrm{m}^{2} / \mathrm{g}\right]\end{array}$ & Sample & $\begin{array}{c}28 \text { days } \\
{\left[\mathrm{N} / \mathrm{mm}^{2}\right]}\end{array}$ \\
\hline $\mathrm{Nano}^{-\mathrm{SiO}_{2}}$ & $10-20$ & 250 & $\mathrm{R}$ & 63.45 \\
$\mathrm{Nano}_{2} \mathrm{Al}_{2} \mathrm{O}_{3}$ & $<50$ & $50-245$ & $\mathrm{~S}_{1}$ & 73.87 \\
$\mathrm{Nano}_{2} \mathrm{Fe}_{2} \mathrm{O}_{3}$ & 13 & $90-110$ & $\mathrm{~A}_{1}$ & 73.23 \\
& & & $\mathrm{~F}_{1}$ & 70.14
\end{tabular}

\section{Discussion and conclusion}

As can be seen from Fig. 4, 1\% nanopowders added cementitious materials gave higher mechanical strength results with respect to reference. They are within the limits of both European and Turkish standards. Nanopowders filled into the pores in cement and as a result of this more higher durability cementitious materials are obtained. Nanosized structures such as nanopowders have a very large surface-to-volume ratios. That is why nanopowders are being used as cement replacing the materials for producing ecologic concrete.

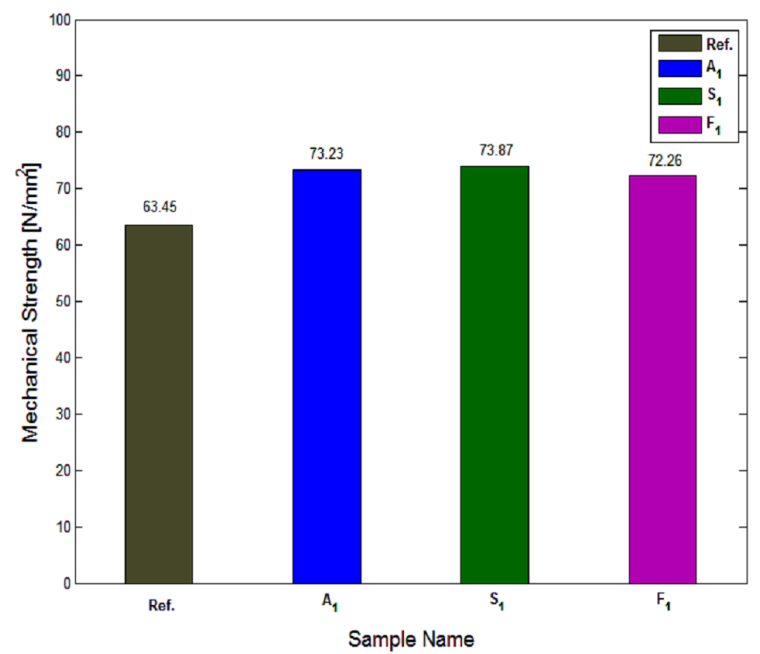

Fig. 4. Mechanical strength of cement samples.

From Fig. 2 linear attenuation coefficients for the samples are in good agreement for the high energies with XCOM calculations. In Fig. 3 measured and calculated HVL and TVL results are displayed. It can be seen that from this figure both experimental and theoretical values fit well.

The purpose of this study was to investigate both mechanical treatment and radiation shielding property of nanosized powders added cementitious materials. The results of this study agree well with the theoretical ones. Furthermore, mechanical treatment results are good for 
the samples to be used as a constructing material. Our future work will be focused on the energy absorption in attempt to evaluate different nanosized powders added cementitious materials radiation shielding purposes.

\section{References}

[1] K. Singh, S. Singh, A.S. Dhaliwal, G. Singh, Appl. Radiat. Isotopes 95, 174 (2015).

[2] I. Akkurt, K. Günoğlu, C. Başyiğit, A. Akkaş, Acta Phys. Pol. A 123, 374 (2013).

[3] I. Akkurt, A. Elkhayat, Ann. Nucl. En. 51, 5 (2013).

[4] A.M. El-Khayatt, Ann. Nucl. En. 37, 991 (2010).

[5] O. İçelli, K.S. Mann, Z. Yalçın, S. Oral, V. Karakaya, Ann. Nucl. En. 55, 341 (2013).
[6] B. Buyuk, A.B. Tugrul, S. Aktop, A.O. Addemir, Acta Phys. Pol. A 123, 177 (2013).

[7] I. Akkurt, H. Akyıldırım, B. Mavi, S. Kilincarslan, C. Basyigit, Ann. Nucl. En. 37, 910 (2010).

[8] J.M. Sharaf, H. Saleh, Radiat. Phys. Chem. 110, 87 (2015).

[9] K.M.A. Hossain, Cem. Concr. Res. 34, 283 (2004).

[10] M.E. Medhat, Ann. Nucl. En. 36, 849 (2009).

[11] I.I. Bashter, Ann. Nucl. En. 24, 1389 (1997).

[12] T. Mutuk, M.Sc. Thesis, Ondokuz Mayis University, Turkey.

[13] M.J. Berger, J.H. Hubbell, S.M. Seltzer, J. Chang, J.S. Coursey, R. Sukumar, D.S. Zucker, K. Olsen, XCOM: photon crossection database, U.S. 